\title{
Usahatani Organik Padi Putih dan Padi Hitam: Pendekatan Pendapatan, Fungsi Produksi Cobb-Douglas dan VPM
}

\author{
Annita Rahmawati, Agustono*, Raden Kunto Adi \\ Program Studi Agribisnis, Fakultas Pertanian, Universitas Sebelas Maret \\ *Corresponding author: agustono0108@gmail.com
}

\begin{abstract}
This research aims to determine of (1) the productivity, income and efficiency of organic white paddy and organic black paddy and (2) the influence of production factors to production the white paddy and organic black paddy. The location of the research in Karanganyar, Central Java.The method of sampling was quota sampling with 30 respondents in each organic paddy, while the technique to collect respondents was conducted by purposive sampling. Data used in the study were primary and secondary data. Method of data analysis used in this research was (1) the analysis of productivity, income and efficiency of farming, (2) Cobb-Douglass and VPM (Varying Parameter Model) to determine the influence of factors to the production of organic white paddy and black paddy.The results of research on the analysis of productivity of organic white paddy were 95,19 $\mathrm{kw} / \mathrm{ha} / \mathrm{season}$ and black paddy with the value of 72,53kw/ha/season. Income of organic white paddy was IDR 18,786,63.72/ha/season and income of organic black paddy with the value of IDR 25,641,526,39/ha/season. The efficiency of organic white paddy was 2,97 and the organic black paddy which was 3,83. The results of the Cobb-Douglas analysis showed the production of organic white paddy different from the organic black paddy. VPM showed that the production factor of land area and labor significantly influenced production in organic white rice and organic black rice farming, while seeds and manure were known to only have significant influence toward production in organic white rice.
\end{abstract}

Keywords: Cobb-Douglas; Income; Organic black paddy; Organic white paddy; VPM (Varying Parameter Model)

Cite this as: Rahmawati, A., Agustono, \& Adi, R.K. 2018. Usahatani Organik Padi Putih dan Padi Hitam: Pendekatan Pendapatan, Fungsi Produksi Cobb-Douglas dan VPM. Caraka Tani: Journal of Sustainable Agriculture. 33(1), 8-18. doi:http://dx.doi.org/10.20961/carakatani.v33i1.19358

\section{PENDAHULUAN}

Basis dari pembangunan keberlanjutan menurut Turner et al. (1992) ialah pemerataan antar dan inter generasi dengan mempertemukan semua masyarakat dalam tujuan keberlanjutan. Keberlanjutan atau sustainable menurut Rigby dan Cacares (2001) diadopsi dari bahasa latin sustenere yang berarti tetap ada, yang implikasinya berupa dukungan secara permanen dan jangka panjang. Emas (2015) menyatakan tujuan pembangunan keberlanjutan dalam jangka panjang ialah stabilitas dari ekonomi dan lingkungan. Pearce dan Turner (1990) menyatakan terkait aturan dalam keberlanjutan yaitu (1) bagi sumberdaya yang dapat diperbaharui tingkat pemanenan tidak melebihi tingkat pertumbuhan dan (2) limbah yang dibuang ke lingkungan tidak melebihi daya asimilasi dari lingkungan. Di sisi lain Tietenberg dan Lewis (2012) menambahkan bahwa pertumbuhan berkelanjutan dari kesejahteraan akan terjadi apabila (1) pertumbuhan sumberdaya melebihi jumlah discount rate dan pertumbuhan penduduk dan (2) supply makanan cukup untuk memenuhi kebutuhan penduduk.

Terkait dengan pertanian, Velten et al. (2015) menyatakan kemampuan pertanian mendukung penyedian pangan dan sumberdaya lainnya bagi penduduk dan aktivitasnya merupakan masalah yang krusial. Terano (2015) menyatakan bahwa penggunaan pestisida, herbisida dan pemberantasan gulma dari bahan kimia sintetik menurunkan kehilangan produksi dan meningkatkan produktivitas. Namun demikian memberikan dampak buruk bagi lingkungan. 
Salah satu cara yang dapat dilakukan ialah dengan mengembangkan pertanian organik. Dlumini et al. (2014) menyatakan pertanian organik merupakan sistem pertanian yang tidak menggunakan kimia sintetis dan perubahan genetik. Krall (2015) pertanian organik merupakan pertanian yang tidak menggunakan pestisida sintetik dan pupuk mineral tetapi berusaha untuk bekerja dengan cara alamiah dan siklus. Tietenberg dan Lewis (2012) menyatakan produksi pangan dengan cara organik akan menurunkan kerusakan lingkungan. Untuk itu diperlukan budidaya padi sebagai penyedia pangan dan sumber input untuk industri lain yang ramah dengan lingkungan.

Santoso (2012) menyatakan tranformasi budidaya padi dalam rangka untuk mempertemukan kebutuhan manusia sangat diperlukan. Disisi lain upaya meningkatkan pendapatan petani padi masih terkendala, seperti: (1) menurunnya kesehatan dan kesuburan tanah, (2) kecenderungan meningkatnya hasil padi bersifat stagnan, (3) penggunaan bahan kimia anorganik yang lebih banyak dan lebih banyak lagi dan (4) perilaku petani yang tidak bijaksana dalam memanfaatkan sumberdaya lokal.

Manfaat dari pertanian organik, menurut Santosa (2012) dari hasil penelitianya di Ciamis menyebutkan bahwa budidaya padi organik mampu meningkatkan produksi dari 5,440 ton/ha menjadi 9,733 ton/ha GKP. Surekha et al. (2013) di India, profitability dari budidaya padi organik lebih besar dibanding budidaya padi konvensional, dan juga berkontribusi terhadap kesehatan, lingkungan dan keberlanjutan pembangunan pertanian. Prihtanti (2016) menyatakan di Kabupaten Karanganyar hasil padi organik memberi nilai ekonomi yang lebih besar pada produk makanan dan menyerap tenaga kerja yang lebih besar dibanding budidaya padi konvensional. Menurut Sulistyana (2014), alasan utama konsumen membeli padi organik adalah karena alasan kesehatan. Aufanada et al. (2017) menyatakan $82 \%$ konsumen di Jakarta Selatan bersedia membayar lebih tinggi dari harga pasaran terhadap produk organik dengan kisaran $8,5 \%$ sampai $15 \%$.

Terkait dengan budidaya padi organik, pengetahuan terhadap hubungan input-ouput sangat diperlukan, seperti pendapat Beatie dan Taylor (1996) yang menyebutkan pengetahuan terhadap hubungan input-output merupakan kekuatan yang akan menentukan produksi. Debertin (2012) menyatakan hubungan input- output merupakan fungsi yang menggambarkan teknik hubungan transformasi input menjadi output. Cobb dan Douglas (1928) menyatakan bahwa hubungan input-output berguna untuk (1) mengukur perubahan input terhadap ouput dan (2) untuk menentukan hubungan antara input dengan output.

Variying Parameter Model (VPM) merupakan metode untuk mengetahui hubungan input-output, dengan syarat jika penggunaan variabel dummy pada model Cobb-Douglas berpengaruh nyata. VPM merupakan model dengan dummy elastisitas. Ekananda (2015) menyatakan prinsip utama dalam analisis dengan dummy elastisitas ialah menganalisis adanya perbedaaan dampak variabel menurut kelompok tertentu yang dipisahkan melalui data pada dummy variable. VPM telah digunakan oleh Sanim dan Sugema (1996) untuk membedakan antara IPM dengan non-IPM terkait hubungan input dengan output. Variabel dummy dalam penelitian ialah jenis padi yaitu putih dan hitam.

Penelitian ini bertujuan untuk mengetahui: (1) produktivitas, pendapatan dan efisiensi usahatani padi organik putih dan hitam, dan (2) mengetahui pengaruh fakor produksi terhadap produksi padi organik putih dan hitam.

\section{METODE PENELITIAN}

Penelitian ini dilakukan di Kabupaten Karanganyar, karena Kabupaten Karanganyar mempunyai beberapa sentra produksi beras organik yang tersebar di Kecamatan Mojogedang, Kecamatan Karangpandan, Kecamatan Matesih dan Kecamatan Jenawi. Penentuan Kecamatan tersebut sebagai lokasi penelitian dengan mempertimbangkan bahwa di lokasi ini terdapat Kelompok Tani yang mengembangkan usahatani organik padi putih dan usahatani organik padi hitam yang telah diakui oleh SNI dan tersertifikasi pangan organik oleh Lembaga Sertifikasi Organik Seloliman (LeSOS).

Petani yang dijadikan responden sebanyak 30 orang yang berusahatani organik padi putih dan 30 orang yang berusahatani organik padi hitam. Petani sebagai responden dilakukan dengan sengaja (purposive sampling), Irianto dan Mardikanto (2011) pemilihan secara sengaja merupakan pemilihan berdasarkan pilihan-pilihan dengan memperhatikan karakteristik yang dimiliki calon responden yang sesuai dengan tujuan penelitian. Pelaksanaanya peneliti meminta 
rekomendasi dari ketua kelompok tani untuk menentukan petani responden. Hal ini dikarenakan persebaran petani yang berusahatani organik padi putih dan berusahatani organik padi hitam bukan hanya pada satu kelompok tani maupun desa saja, selain itu pemilihan jenis padi yang ditanam dan waktu tanam setiap petani berbeda sehingga perlu ada konfirmasi kepada ketua kelompok tani untuk mengetahui petani mana yang menanam jenis padi terkait pada masa tanam pertama.

Data yang digunakan meliputi: (1) data primer dan (2) data sekunder. Data primer diperoleh dari wawancara dengan petani terkait kegiatan usahatani organik padi putih atau usahatani organik padi hitam pada musim tanaman November 2016 - Januari 2017. Data sekunder diperoleh dari instansi yang terkait seperti BPS, Dinas Pertanian Unit Tanaman Pangan dan Hortikultura Karanganyar dan kelompok tani. Pelaksanaan penelitian dilakukan dengan metode survei.

\section{Metode Analisis Data}

Metode analisis data yang digunakan dalam penelitian ini meliputi 1) Produktivitas lahan (kw/ha); 2) Analisis pendapatan dihitung dengan mengurangkan penerimaan dengan biaya mengusahakan mengacu pada konsep dari Suratiyah (2015). Formulasi matematisnya adalah $P=R-B m$ dan analisis efisiensi dengan menggunakan pendekatan RC ratio. Formulasi matematisnya ialah $=R / B m$. Keterangan, $\mathrm{P}$ ialah pendapatan, $\mathrm{R}$ ialah penerimaan dan $\mathrm{Bm}$ ialah biaya mengusahakan.

Model untuk mengetahui pengaruh faktor produksi terhadap produksi digunakan fungsi produksi Cobb-Douglas dengan variabel dummy, yang mangacu pada Sanim dan Sugema (1996).

$$
\begin{aligned}
\log Y= & \alpha+\beta 1 \log X_{1}+\beta 2 \log X_{2}+\beta 3 \log X_{3} \\
& +\beta 4 \log X_{4}+\beta 5 \log X_{5}+\beta 6 \log \\
& X_{6}+D_{1}+e
\end{aligned}
$$

dengan $\mathrm{Y}$ merupakan jumlah produksi, $\mathrm{X}_{1}$ ialah luas lahan, $X_{2}$ ialah Un jumlah tenaga kerja, $X_{3}$ ialah jumlah benih, $X_{4}$ ialah pupuk kandang, $X_{5}$ ialah pupuk organik, $X_{6}$ ialah pestisida organik, $\beta$ merupakan koefisien regresi masing-masing faktor yang sekaligus menunjukkan besar elastisitas produksi, $\mathrm{D}_{1}$ (1: padi hitam, 0: padi putih), e ialah kesalahan.
Model untuk mengetahui pengaruh faktor produksi dalam usahatani organik pada masingmasing kelompok penggunaan jenis padi putih maupun padi hitam dengan menggunakan VPM (Variying Parameter Model). Modelnya ialah:

$\log Y=\beta_{10} \log X_{1}+\beta_{11} D_{1} \log X_{1}+\beta_{20} \log X_{2}+$ $\beta_{21} D_{1} \log X_{2}+\beta_{30} \log X_{3}+\beta_{31} D_{1} \log X_{3}+$ $\beta_{40} \log X_{4}+\beta_{41} D_{1} \log X_{4}+\beta_{50} \log X_{5}+$ $\beta_{51} D_{1} \log X_{5}+\beta_{60} \log X_{6}+\beta_{61} D_{1} \log X_{6}+\beta_{0}+$ $\mathrm{e}, \mathrm{i}>1$

Untuk mengetahui kebaikan model dan pengaruh factor-faktor berupa luas lahan $\left(\mathrm{X}_{1}\right)$, tenaga kerja $\left(\mathrm{X}_{2}\right)$, jumlah benih $\left(\mathrm{X}_{3}\right)$, pupuk kandang $\left(\mathrm{X}_{4}\right)$, pupuk organik $\left(\mathrm{X}_{5}\right)$, pestisida organik $\left(\mathrm{X}_{6}\right)$, dan jenis padi $\left(\mathrm{D}_{1}\right)$ dalam menjelaskan variasi faktor jumlah produksi (Y) dilakukan beberapa pengujian. Pengujian yang dilakukan meliputi: Koefisien determinasi $\left(\mathrm{R}^{2}\right)$, Uji $F$ dan Uji $t$ serta pengujian terkait kaidah asumsi klasik:

a. Koefisien determinasi $\left(\mathrm{R}^{2}\right)$ digunakan untuk mengukur kemampuan model untuk menerangkan variasi faktor dependen. Nilai koefisien determinasi adalah antara nol dan satu, semakin tinggi nilai koefisien determinasi maka faktor berupa luas lahan $\left(\mathrm{X}_{1}\right)$, tenaga kerja $\left(\mathrm{X}_{2}\right)$, jumlah benih $\left(\mathrm{X}_{3}\right)$, pupuk kandang $\left(\mathrm{X}_{4}\right)$, pupuk organik $\left(\mathrm{X}_{5}\right)$, pestisida organiki $\left(\mathrm{X}_{6}\right)$, dan jenis padi $\left(\mathrm{D}_{1}\right)$ semakin mampu memberikan informasi yang dibutuhkan untuk menjelaskan variasi faktor jumlah produksi (Y).

b. Uji signifikansi simultan atau uji statistik $F$ digunakan untuk mengetahui apakah semua faktor yang berupa luas lahan $\left(\mathrm{X}_{1}\right)$, tenaga kerja $\left(\mathrm{X}_{2}\right)$, jumlah benih $\left(\mathrm{X}_{3}\right)$, pupuk kandang $\left(\mathrm{X}_{4}\right)$, pupuk organik $\left(\mathrm{X}_{5}\right)$, pestisida organik $\left(\mathrm{X}_{6}\right)$, dan jenis padi $\left(\mathrm{D}_{1}\right)$ mempunyai pengaruh secara bersama-sama atau simultan terhadap variabel jumlah produksi (Y).

c. Uji satatistik t digunakan untuk menunjukkan seberapa jauh pengaruh satu faktor berupa luas lahan $\left(\mathrm{X}_{1}\right)$, atau tenaga kerja $\left(\mathrm{X}_{2}\right)$, atau jumlah benih $\left(\mathrm{X}_{3}\right)$, atau pupuk kandang $\left(\mathrm{X}_{4}\right)$, atau pupuk organik $\left(\mathrm{X}_{5}\right)$, pestisida organik $\left(\mathrm{X}_{6}\right)$, dan jenis padi $\left(D_{1}\right)$ terhadap faktor jumlah produksi $\mathrm{Y}$ dan menganggap faktor lainnya konstan.

d. Uji Multikolinearitas dilakukan dengan melihat varians inflation factor (VIF) jika lebih besar dari 10 maka faktor tersebut 
mempunyai persoalan multikolinearitas (Prayitno, 2009).

e. Uji Heteroskedastisitas dilakukan dengan melihat pola titik-titik pada grafik scatterplot. Kriteria adalah jika terdapat pola tertentu maka terjadi heteroskedastisitas, jika tidak terdapat pola yang jelas maka tidak terjadi heteroskedastisitas (Prayitno, 2009).

f. Uji Autokorelasi dilakukan dengan memperhatikan nilai Durbin-Watson, kriteria: $\mathrm{du}<\mathrm{dw}<4-\mathrm{du}$, dengan $\alpha 5 \%$ (Ghozali, 2014).

g. Uji Normalitas dengan uji Kolmogorov Smirnov pada $\alpha 5 \%$ dengan kriteria pengujian normalitas data adalah jika $\rho>\alpha$ artinya data terdistribusi normal, jika $\rho<\alpha$ artinya data tidak terdistribusi normal (Ghozali, 2014).

\section{HASIL DAN PEMBAHASAN}

\section{Faktor Produksi dan Produktivitas Padi Organik}

Faktor produksi yang diteliti pada usahatani organik padi putih dan usahatani organik padi hitam meliputi: benih, pupuk kandang, pupuk organik buatan sendiri dan buatan pabrik, pestisida organik dan tenaga kerja dari luar keluarga dan dari dalam keluarga. Banyaknya pengunaan faktor produksi disajikan pada Tabel 1.

Tabel 1. Penggunaan Faktor Produksi dan Tenaga Kerja pada Usahatani Organik Padi Putih dan Usahatani Organik Padi Hitam di Karanganyar Tahun 2017

\begin{tabular}{llcccc}
\hline \multirow{2}{*}{ No. } & \multicolumn{1}{c}{ Uraian } & \multicolumn{2}{c}{$\begin{array}{c}\text { Usahatani Organik } \\
\text { Padi Puth }\end{array}$} & \multicolumn{2}{c}{$\begin{array}{c}\text { Usahatani Organik } \\
\text { Padi Hitam }\end{array}$} \\
\cline { 2 - 6 } & & Per UT & Per Ha & Per UT & Per Ha \\
\hline 1. & Benih (kg) & 11,82 & 44,65 & 10,80 & 33,04 \\
2. & Pupuk Kandang (kw) & 8,14 & 30,76 & 13,57 & 41,51 \\
3. & Pupuk Organik & 4,39 & 16,57 & 5,41 & 16,55 \\
& $\begin{array}{l}\text { a. POC (lt) } \\
\text { b. Petroganik (sak) }\end{array}$ & 1,20 & 4,53 & 0,80 & 2,45 \\
4. & Pestisida Organik (lt) & 1,26 & 4,74 & 2,25 & 6,90 \\
5. & Tenaga kerja keluarga & 34,67 & 131,00 & 40,66 & 124,39 \\
& (HKP) & & & & \\
6. & Tenaga kerja keluarga & 8,35 & 31,56 & 9,39 & 28,70 \\
& (HKP) & & & & \\
\hline
\end{tabular}

Sumber: Analisis Data Primer

Tabel 1 menunjukkan jumlah penggunaan benih pada usahatani organik padi hitam lebih rendah sebesar 11,61 $\mathrm{kg} / \mathrm{ha}$ dibandingkan usahatani organik padi putih. Penyebabnya ialah petani yang berusahatani organik padi hitam menerapkan sistem tanam satu bibit satu lubang, sedangkan pada usahatani organik padi putih menerapkan sistem tanam konvensional yaitu lebih dari satu bibit pada satu lubang tanam.

Penggunaan pupuk kandang pada usahatani organik padi hitam lebih tinggi $10,75 \mathrm{kw} / \mathrm{ha}$ daripada penggunaan pupuk kandang pada usahatani padi organik putih. Pupuk kadang yang digunakan berasal dari kotoran ternak seperti sapi maupun unggas. Petani yang berusahatani organik padi putih dan yang berusahatani organik padi hitam umumnya mempunyai ternak yang kotorannya dapat dimanfaatkan untuk pupuk.
Pupuk organik yang digunakan meliputi pupuk organik cair dan petroganik. Pupuk organik cair dihasilkan dari fermentasi bahan organik yang dibuat sendiri oleh petani maupun secara berkelompok di kelompok tani. Bahan untuk pembuatan pupuk organik cair berasal dari bahan yang tersedia di lingkungan sekitar meliputi: urine sapi, air kelapa, tetes tebu, akar bambu dan alangalang. Kebutuhan pupuk organik yang lebih tinggi pada usahatani organik padi hitam disebabkan karena masa tanam yang lebih panjang, selain itu petani yang berusahatani organik padi hitam cenderung lebih memilih menggunakan pupuk organik yang dibuat sendiri daripada membeli pupuk organik buatan pabrik seperti petroganik. Penggunaan pupuk petroganik pada usahatani organik padi hitam lebih rendah daripada pada usahatani organik padi putih. Petani yang berusahatani organik padi putih dan berusahatani 
organik padi hitam memilih menggunakan petroganik kerena lebih praktis. Harga dari pupuk petroganik per sak (40 kg) sebesar Rp 20.000,-. Pemberian pupuk petroganik bertujuan untuk melengkapi nutrisi yang diperlukan oleh tanaman padi organik seperti N, P dan K.

Penggunaan pestisida organik pada usahatani organik padi putih dan usahatani organik padi hitam dilakukan dengan memperhatikan kondisi hama dan penyakit tanaman. Pestisida organik dibuat secara manual oleh petani dengan memanfaatkan bahan yang mudah didapatkan dari lingkungan sekitar. Bahan yang digunakan ialah akar alang-alang, akar jambe dan air kelapa, sedangkan bahan yang diperoleh dengan membeli seperti cabai, merica, alkohol dan tetes tebu. Jumlah penggunaan pestisida organik pada usahatani organik padi hitam lebih tinggi dibanding usahatani organik padi putih. Perbedaan disebabkan oleh penggunaan bahan pada pestisida organik yang berbeda-beda setiap petani, sehingga kualitas dan konsentrasi kepekatan pestisida organik berbeda. Faktor lainnya ialah hama yang menyerang pada usahatani organik padi hitam umumnya adalah tikus, wereng dan burung, sehingga petani menanggulanginya dengan memasang jebakan untuk tikus, sedangkan untuk wereng tidak terlalu banyak sehingga kualitas pestisida organik yang digunakan dapat diturunkan. Serangan hama pada usahatani organik padi putih cenderung lebih didominasi oleh wereng sehingga petani lebih memperhatikan komposisi pestisida organik yang akan diaplikasikan.

Petani lebih banyak menggunakan tenaga kerja luar sekitar $80,6 \%$ untuk usahatani organik padi putih dan $81,3 \%$ untuk usahatani organik padi hitam. Hal ini menunjukkan uasahatani organik padi hitam akan menyerap tenaga kerja luar yang lebih banyak, sehingga membuka kesempatan kerja bagi masyarakat sekitar.

\section{Biaya Usahatani}

Biaya mengusahakan dikelompokkan menjadi biaya alat-alat luar dan biaya tenaga kerja dalam keluarga. Biaya alat-alat luar meliputi biaya saprodi, biaya tenaga kerja luar dan biaya lainlain.

Tabel 2. Biaya Mengusahakan Usahatani Organik Padi Putih dan Usahatani Organik Padi Hitam di Karanganyar Tahun 2017

\begin{tabular}{|c|c|c|c|c|c|}
\hline \multirow[t]{2}{*}{ No. } & \multirow[t]{2}{*}{ Uraian } & \multicolumn{2}{|c|}{$\begin{array}{c}\text { Biaya Mengusahakan } \\
\text { Usahatani OrganikPadi Putih } \\
\text { (Rp) }\end{array}$} & \multicolumn{2}{|c|}{$\begin{array}{c}\text { Biaya Mengusahakan } \\
\text { Usahatani Organik Padi Hitam } \\
\text { (Rp) }\end{array}$} \\
\hline & & Per UT & Per Ha & Per UT & Per Ha \\
\hline 1. & Benih $(\mathrm{kg})$ & $69.366,67$ & $262.090,68$ & $69.116,67$ & $211.473,74$ \\
\hline 2. & Pupuk Kandang (kw) & $67.813,33$ & $256.221,66$ & $107.616,67$ & $329.270,78$ \\
\hline \multirow[t]{3}{*}{3.} & Pupuk Organik & & & & \\
\hline & a. $\mathrm{POC}$ (lt) & $30.974,14$ & $117.030,75$ & $47.321,67$ & $144.788,37$ \\
\hline & b. Petroganik (sak) & $24.000,00$ & $90.680,10$ & $16.000,00$ & $48.954,61$ \\
\hline 4 & Pestisida Organik (lt) & $18.785,00$ & $70.976,07$ & $18.556,33$ & $56.776,13$ \\
\hline 5 & Tenaga kerja luar keluarga & $1.733 .441,67$ & $6.549 .527,71$ & $2.032 .808,33$ & $6.219 .709,33$ \\
\hline 6 & Biaya lain-lain & $165.014,91$ & $623.482,03$ & $224.172,30$ & $685.891,76$ \\
\hline 7 & Tenaga kerja keluarga & $417.700,00$ & $1.578 .211,58$ & $468.875,00$ & $1.434 .599,69$ \\
\hline \multicolumn{2}{|c|}{ Rata-rata per MT } & $2.527 .095,72$ & $9.548 .220,58$ & $2.984 .466,96$ & $9.131 .464,41$ \\
\hline
\end{tabular}

Sumber: Analisis Data Primer

Biaya yang dikeluarkan untuk tenaga kerja luar sebesar mencapai $68,6 \%$ untuk usahatani organik padi putih dan $68,1 \%$ untuk usahatani organik padi hitam. Hal ini menunjukan manfaat yang diterima oleh tenaga kerja luar ialah yang terbesar.

\section{Penerimaan}

Perhitungan penerimaan menggunakan standar harga beras. Tahapan perhitungan ialah (1) gabah kering panen (GKP) apabila dijadikan GKG dikalikan faktor konversi sebesar 86,02\%, (2) GKG apabila dijadikan beras dikalikan dengan faktor konversi sebesar $62,47 \%$. Selanjutnya dengan mendasarkan standar beras, rincian penerimaan usahatani organik padi putih dan padi hitam disajikan pada Tabel 3. 
Tabel 3. Penerimaan Usahatani Organik Padi Putih dan Usahatani Organik Padi Hitam di Karanganyar Tahun 2017

\begin{tabular}{lrrrr}
\hline \multirow{2}{*}{ Uraian } & \multicolumn{2}{c}{ Usahatani Organik Padi Putih } & \multicolumn{2}{c}{ Usahatani Organik Padi Hitam } \\
\cline { 2 - 5 } & \multicolumn{1}{c}{ Per UT } & \multicolumn{1}{c}{ Per Ha } & \multicolumn{1}{c}{ Per UT } & \multicolumn{1}{c}{ Per Ha } \\
\hline Produksi (kg) & 714,22 & $2.698,56$ & 649,43 & $1.987,03$ \\
Harga (Rp/kg) & $10.500,00$ & $10.500,00$ & $17.000,00$ & $17.000,00$ \\
\hline Penerimaan per MT (Rp/MT) & $7.499 .292,50$ & $28.334 .858,31$ & $11.364 .972,50$ & $34.772 .990,82$ \\
\hline Penerimaan per Bulan (Rp/Bln) & $2.499 .764,16$ & $9.444 .952,77$ & $3.247 .135,00$ & $9.935 .140,23$ \\
\hline
\end{tabular}

Sumber: Analisis Data Primer

Produktivitas dengan menggunakan standar gabah kering panen (GKP) untuk padi putih sebesar $95,19 \mathrm{kw} / \mathrm{ha}$ dan untuk padi hitam sebesar $72,53 \mathrm{kw} / \mathrm{ha}$. Padi putih menghasilkan lebih banyak sebesar $22,7 \mathrm{kw} / \mathrm{ha}$ atau $27,1 \%$ dibanding padi hitam. Jika dibanding dengan hasil dari Santoso (2012) masih lebih rendah. Harga beras padi hitam sebesar Rp 17.000/kg sedang beras putih harganya $\mathrm{Rp} 10.500 / \mathrm{kg}$, dengan selisih $\mathrm{Rp}$ 6.500 atau $61,8 \%$ beras hitam lebih mahal dibanding beras putih. Penerimaan petani yang berusahatani organik padi hitam lebih besar dibanding petani yang berusahatani organik padi putih.

\section{Pendapatan dan Efisiensi}

Selanjutnya analisis pendapatan dan efisiensi usahatani organik padi putih dan usahatani organik padi hitam disajikan pada Tabel 4.

Tabel 4. Pendapatan dan Efisiensi Usahatani Organik Padi Putih dan Usahatani Organik Padi Hitam di Karanganyar Tahun 2017

\begin{tabular}{lrrrr}
\hline \multirow{2}{*}{ Uraian } & \multicolumn{2}{c}{ Usahatani Organik Padi Putih } & \multicolumn{2}{c}{ Usahatani Organik Padi Hitam } \\
\cline { 2 - 5 } & \multicolumn{1}{c}{ Per UT } & \multicolumn{1}{c}{ Per Ha } & \multicolumn{1}{c}{ Per UT } & \multicolumn{1}{c}{ Per Ha } \\
\hline Penerimaan (Rp) & $7.499 .292,50$ & $28.334 .858,31$ & $11.364 .972,50$ & $34.772 .990,82$ \\
Biaya mengusahakan (Rp) & $2.527 .095,72$ & $9.548 .220,59$ & $2.984 .466,96$ & $9.131 .464,43$ \\
Pendapatan per MT (Rp/MT) & $4.972 .196,78$ & $18.786 .637,72$ & $8.380 .505,54$ & $25.641 .526,39$ \\
Pendapatan per Bln (Rp/Bln) & $1.657 .398,92$ & $6.262 .212,57$ & $2.394 .430,15$ & $7.326 .150,39$ \\
Efisiensi & & 1,96 & & 2,80 \\
\hline
\end{tabular}

Sumber: Analisis Data Primer

Tabel 4 menunjukkan pendapatan bersih usahatani organik padi hitam lebih besar dibanding putih, dengan selisih sebesar $\mathrm{Rp}$ $6.854 .888,67 / \mathrm{ha} /$ musim atau $35,5 \%$. Selanjutnya apabila dikonversi ke bulan untuk usahatani organik hitam lebih besar dibanding padi putih dengan perbedaan sebesar Rp 1.063.937,82 atau 17\%. Pearce dan Turner (1990) menyatakan salah satu tolok ukur tentang standar kehidupan terkait dengan pendapatan, sejalan dengan itu maka pendapatan usahatani organik padi hitam lebih tinggi dibanding usahatani organik padi putih. Dengan demikian usahatani organik padi hitam memberikan kontribusi terhadap standar kehidupan yang lebih baik. Selanjutnya Pearce dan Turner (1990) menyatakan pentingnya perbaikan efisiensi dalam rangka untuk meningkatan standar kehidupan. Tabel 4 juga menunjukkan bahwa efisiensi padi hitam lebih baik dibanding padi putih. Dengan demikian usaha budidaya padi hitam mampu memanfaatkan sumberdaya yang lebih sedikit tetapi mampu menghasilkan yang lebih banyak. Teitenberg dan Lewis (2012) menyatakan perbaikan efisiensi akan berpengaruh terhadap perbaikan sustainability.

\section{Fungsi Produksi Cobb-Douglas \\ a. Uji Asumsi Klasik Uji Multikolinearitas}

Uji multikolinearitas dilakukan dengan melihat nilai VIF pada masing-masing variabel bebas. 
Tabel 5. Nilai VIF pada Variabel Bebas

\begin{tabular}{|c|c|}
\hline Variabel & Nilai VIF \\
\hline Luas lahan (X1) & 8,334 \\
\hline Tenaga Kerja (X2) & 8,434 \\
\hline Jumlah Benih (X3) & 2,954 \\
\hline Pupuk Kandang (X4) & 1,702 \\
\hline Pupuk Organik (X5) & 1,026 \\
\hline Pestisida Nabati (X6) & 1,262 \\
\hline Jenis Padi $\left(D_{1}\right)$ & 1,172 \\
\hline
\end{tabular}

Sumber: Analisis Data Primer

Berdasarkan Tabel 5 dapat diketahui bahwa tidak terdapat multikolinearitas pada variabelvariabel bebas yang diteliti.

\section{Uji Heteroskedastisitas}

Dependent Variable: LogY

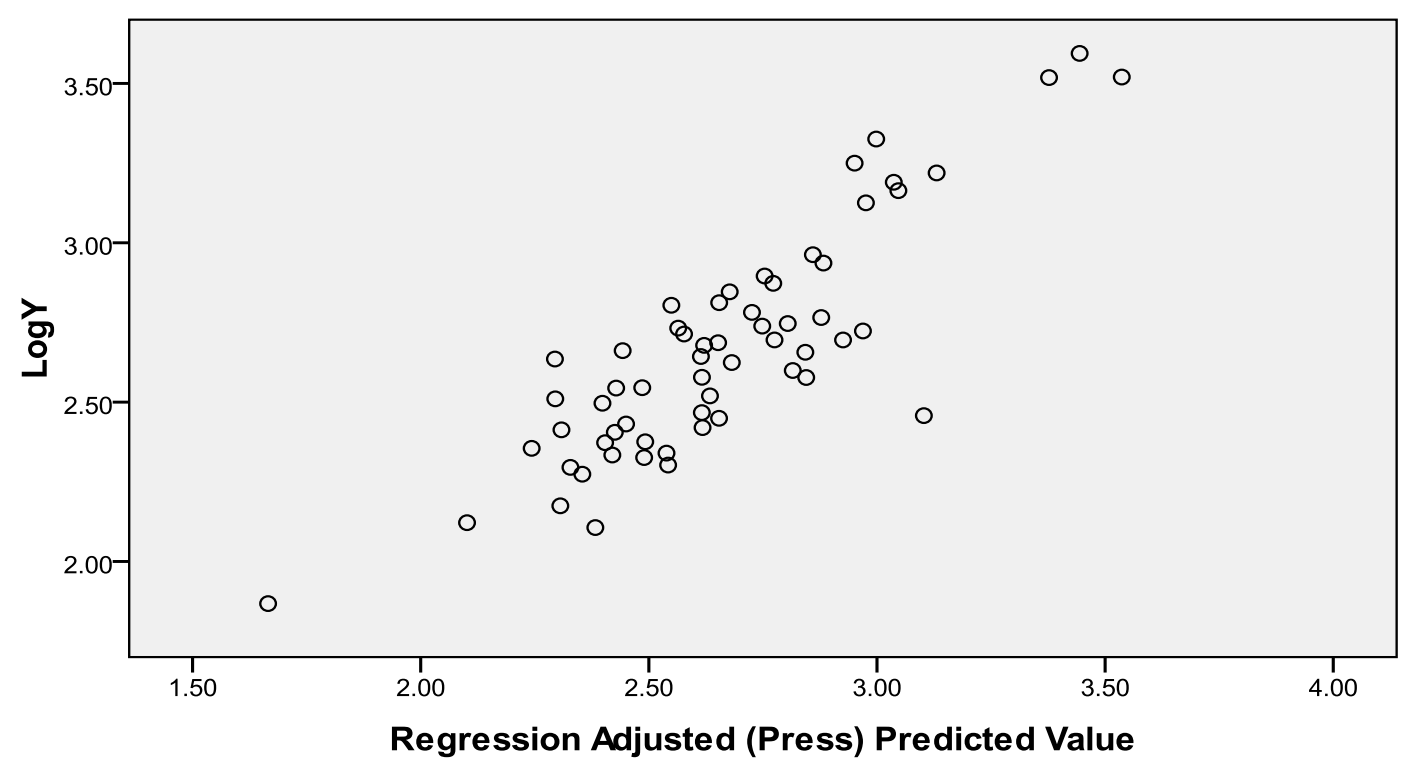

Gambar 1. Hasil Uji Heteroskedastisitas

Berdasarkan Gambar 1. dapat diketahui bahwa tidak terdapat pola tertentu, hal ini menunjukkan tidak terdapat permasalahan heteroskedastisitas pada data yang diteliti.

\section{Uji Autokorelasi}

Pengujian dilakukan dengan memperhatikan nilai Durbin-Watson. Nilai Durbin-Watson adalah 2.118. Nilai du pada tabel Durbin-watson adalah 1.850, sehingga diketahui nilai 4-du adalah 2.150. Hal ini menunjukkan tidak ada masalah autokorelasi karena nilai DW lebih besar dari du dan kurang dari 4-du.

\section{Uji Normalitas}

Hasil pengujian Kolmogorov Smirnov disajikan dalam Tabel 6. Berdasarkan Tabel 6 dapat diketahui bahwa nilai sig. (2-tailed) adalah 0,744 dimana nilai ini lebih besar daripada $\alpha=0,1$ sehingga tidak signifikan. Hal ini menunjukkan bahwa $\mathrm{H}_{0}$ diterima yaitu residual terdistribusi secara normal. 
Tabel 6. Hasil Pengujian Kolmogorov-Smirnov

\begin{tabular}{llr}
\hline $\mathrm{N}$ & & Unstandarized Residual \\
Normal Parameters & Mean & 60 \\
& Std. Deviation & .0000000 \\
Most Extreme Differrences & Absolute & .15428122 \\
& Positive & .088 \\
Kolmogorov-Smirnov Z & Negative & .065 \\
Asymp. Sig. (2-tailed) & & -.088 \\
& & .680 \\
\hline
\end{tabular}

Sumber: Analisis Data Primer

*tidak signifikan pada $\alpha=0,1$

Hasil uji asumsi klasik menunjukkan bahwa semua hasil pengujian memenuhi kaidah asumsi klasik. Hal ini menunjukkan bahwa model dapat dikategorikan sebagai model yang valid.

\section{b. Uji Statistik}

\section{Koefisien Determinasi}

Nilai dari $\mathrm{R}^{2}$ adalah 0,813 atau $81,3 \%$ menujukkan variasi jumlah produksi (Y) dapat dijelaskan oleh variasi dari variabel dependen yang berupa luas lahan $\left(\mathrm{X}_{1}\right)$, tenaga kerja $\left(\mathrm{X}_{2}\right)$, jumlah benih $\left(\mathrm{X}_{3}\right)$, pupuk kandang $\left(\mathrm{X}_{4}\right)$, pupuk organik $\left(\mathrm{X}_{5}\right)$, pestisida nabati $\left(\mathrm{X}_{6}\right)$ dan jenis padi $\left(D_{1}\right)$, sedangkan sisanya $21,2 \%$ dijelaskan oleh sebab-sebab lain diluar model.

\section{Uji F}

Hasil dari uji $\mathrm{F}$ diperoleh nilai probabilitas sebesar 0,000 artinya semua variabel independen berupa luas lahan $\left(\mathrm{X}_{1}\right)$, tenaga kerja $\left(\mathrm{X}_{2}\right)$, jumlah benih $\left(\mathrm{X}_{3}\right)$, pupuk kandang $\left(\mathrm{X}_{4}\right)$, pupuk organik $\left(\mathrm{X}_{5}\right)$, pestisida nabati $\left(\mathrm{X}_{6}\right)$, dan jenis padi $\left(D_{1}\right)$ secara bersama-sama berpengaruh terhadap variabel jumlah produksi (Y).

\section{Uji t}

Untuk mengetahui bagaimana pengaruh dari masing faktor digunakan uji t. Hasil dari pengujian disajikan pada Tabel 7 .

Tabel 7. Hasil Uji t

\begin{tabular}{|c|c|c|c|c|c|c|}
\hline \multirow{2}{*}{\multicolumn{2}{|c|}{ Model }} & \multicolumn{2}{|c|}{ Unstandarized Coefficients } & \multirow{2}{*}{$\frac{\text { Standardized Coefficients }}{\text { Beta }}$} & \multirow{2}{*}{$\mathrm{t}$} & \multirow{2}{*}{ Sig. } \\
\hline & & B & Std. Error & & & \\
\hline 1 & (Constant) & 2.482 & .429 & & 5.790 & .000 \\
\hline & $\log X_{1}$ & .557 & .174 & .555 & 3.208 & $.002 *$ \\
\hline & $\log X_{2}$ & .489 & .209 & .408 & 2.345 & $.023 *$ \\
\hline & $\log X_{3}$ & -.227 & .141 & -.166 & -1.610 & .113 \\
\hline & $\log _{4}$ & .096 & .061 & .124 & 1.589 & .118 \\
\hline & $\log X_{5}$ & -.020 & .025 & -.050 & -.817 & .417 \\
\hline & $\log _{6}$ & -.008 & .034 & -.016 & -.240 & .811 \\
\hline & $\mathrm{D}_{1}$ & -.093 & .046 & -.131 & -2.022 & $.048 *$ \\
\hline
\end{tabular}

Sumber: Analisis Data Primer

*signifikan pada $\alpha=0,1$

Tabel 7 menunjukkan faktor jenis padi $\left(\mathrm{D}_{1}\right)$ mempunyai nilai $\alpha$ sebesar 0,048 lebih kecil daripada $\alpha=0,1$. Nilai koefisien dummy yang berbeda nyata menunjukkan adanya perbedaan produksi antara jenis padi putih dan padi hitam. Negatifnya koefesien menunjukkan bahwa usahatani organik padi hitam produksinya lebih kecil dibanding uasahatani organik padi putih.

\section{Fungsi Produksi Cobb-Douglas yang diestimasi dengan VPM (Variying Parameter Model)}

Analisis VPM dapat dilakukan apabila faktor

$\mathrm{D}_{1}$ pada fungsi produksi Cobb-Douglas 
berpengaruh nyata terhadap produksi. Tabel 7 menunjukkan $D_{1}$ berpengaruh nyata pada $\alpha$ sebesar 0,1, dengan demikian analisis VPM dapat dilakukan. Hasil analisis VPM disajikan pada Tabel 8.

Tabel 8. Hasil Analisis VPM

\begin{tabular}{clrr}
\hline \multirow{2}{*}{ No. } & \multicolumn{1}{c}{ Variabel } & \multicolumn{2}{c}{$\begin{array}{c}\text { Usahatani Organik } \\
\text { Padi Putih }\end{array}$} \\
\hline 1. & Konstanta & 2.277 & 2.277 \\
& & $(0.000)$ & $(0.000)$ \\
2. & Luas lahan $\left(\mathrm{X}_{1}\right)$ & 0.561 & 0.478 \\
& & $\left(0.019^{*}\right)$ & $\left(0.009^{*}\right)$ \\
3. & Tenaga kerja $\left(\mathrm{X}_{2}\right)$ & 0.780 & 0.513 \\
& & $\left(0.005^{*}\right)$ & $\left(0.055^{*}\right)$ \\
4. & Jumlah benih $\left(\mathrm{X}_{3}\right)$ & -0.479 & -0.214 \\
& & $\left(0.081^{*}\right)$ & $(0.255)$ \\
5. & Pupuk kandang $\left(\mathrm{X}_{4}\right)$ & 0.177 & 0.075 \\
& & $\left(0.091^{*}\right)$ & $(0.317)$ \\
6. & Pupuk organik cair $\left(\mathrm{X}_{5}\right)$ & -0.006 & 0.010 \\
& & $(0.903)$ & $(0.798)$ \\
7. & Pestisida organik $\left(\mathrm{X}_{6}\right)$ & 0.088 & -0.050 \\
& & $(0.117)$ & $(0.322)$ \\
\hline
\end{tabular}

Sumber: Analisis Data Primer

*signifikan pada $\alpha 0,1$

Untuk usahatani organik padi putih ada 4 faktor yang berpengaruh nyata terhadap produksi, yaitu luas lahan, tenaga kerja, benih dan pupuk kandang. Luas lahan berpengaruh positif terhadap produksi, menunjukkan apabila luas bertambah maka produksi akan bertambah. Nilai elastisitas produksi luas lahan sebesar 0,561 , hal ini memberikan makna apabila luas lahan bertambah sebesar 10\% dapat meningkatkan tambahan produksi sebesar 5,61\%. Tenaga kerja berpengaruh positif terhadap produksi, menunjukkan apabila penggunaan tenaga kerja ditambah maka produksi akan bertambah. Nilai elastisitas produksi tenaga kerja sebesar 0,780 , hal ini memberikan makna apabila tenaga kerja bertambah sebesar $10 \%$ dapat meningkatkan tambahan produksi sebesar 7,80\%. Jumlah benih berpengaruh negatif terhadap produksi, menunjukkan apabila penggunan benih ditambah maka akan menurunkan produksi. Nilai elastisitas produksi benih sebesar $-0,479$, hal ini memberikan makna apabila jumlah benih berkurang sebesar 10\% dapat meningkatkan tambahan produksi sebesar 4,79\%. Pupuk kandang berpengaruh positif terhadap produksi, menunjukkan apabila penggunaan pupuk kandang bertambah maka produksi akan bertambah. Nilai elastisitas produksi pupuk kandang sebesar
0,091, hal ini memberikan makna apabila penggunaan pupuk kandang bertambah sebesar $10 \%$ dapat meningkatkan tambahan produksi sebesar $0,091 \%$. Sehubungan dengan itu untuk meningkatkan produksi pada usahatani organik padi putih dilakukan dengan (1) meningkatkan luas lahan, tenaga kerja dan pupuk kandang dan (2) menurunkan jumlah penggunaan benih.

Untuk usahatani organik padi hitam ada 2 faktor yang berpengaruh nyata terhadap produksi, yaitu luas lahan dan tenaga kerja. Luas lahan berpengaruh positif terhadap produksi, menunjukkan apabila penggunaan luas lahan bertambah maka produksi akan bertambah. Nilai elastisitas produksi luas lahan sebesar 0,478, hal ini memberikan makna apabila luas lahan bertambah sebesar $10 \%$ maka dapat meningkatkan tambahan produksi sebesar $4,78 \%$. Tenaga kerja berpengaruh positif terhadap produksi, menunjukkan apabila penggunaan tenaga kerja ditambah maka produksi akan bertambah. Nilai elastisitas produksi tenaga kerja sebesar 0,513, hal ini memberikan makna apabila penggunaan tenaga kerja bertambah sebesar $10 \%$ maka dapat meningkatkan tambahan produksi sebesar 5,13\%. Sehubungan dengan itu untuk meningkatkan produksi pada usahatani organik 
padi hitam, yaitu dengan dengan meningkatkan luas lahan dan jumlah tenaga kerja.

\section{KESIMPULAN DAN SARAN}

\section{Kesimpulan}

Produktivitas padi pada usahatani organik padi putih sebesar 95,19 kw/ha/musim dan usahatani organik padi hitam sebesar $72,53 \mathrm{kw} / \mathrm{ha} / \mathrm{musim}$. Pendapatan pada usahatani organik padi putih sebesar Rp 18.786.63,72/ha/musim dan pendapatan usahatani organik padi hitam sebesar Rp 25.641.526,39/ha/musim. Efisiensi usahatani organik padi putih sebesar 2,97 dan efisiensi usahatani organik padi hitam sebesar 3,83. Faktor produksi berupa luas lahan, tenaga kerja, jumlah benih dan pupuk kandang berpengaruh nyata terhadap produksi padi putih. Elastisitas lahan sebesar 0,561 , tenaga kerja sebesar 0,780 , pupuk kandang sebesar 1,177 dan benih sebesar -0,479. Faktor produksi berupa luas lahan dan tenaga kerja berpengaruh nyata terhadap produksi padi organik hitam. Elastisitas luas lahan sebesar 0,478 dan tenaga kerja sebesar 0,513.

\section{Saran}

Usahatani organik padi putih dan usahatani organik padi hitam memiliki produktivitas yang tinggi, pendapatan yang baik dan efisien, untuk itu usahatani organik padi putih dan usahatani organik padi hitam dijadikan unggulan dan dikembangkan di Kabupaten Karanganyar secara bersama-sama dalam rangka mendukung pertanian berkelanjutan. Untuk usahatani organik padi putih peningkatan produksi dapat dilakukan dengan menambah faktor produksi yaitu lahan, tenaga kerja, dan pupuk kandang serta menurunkan jumlah benih. Untuk usahatani organik padi hitam dengan menambah luas lahan dan tenaga kerja.

\section{DAFTAR PUSTAKA}

Aufanada, V., Ekowati, T., \& Prastiwi, W.D. 2017. Kesediaan Membayar (Willingnes to pay) Konsumen Terhadap Produk Sayur Organik di Pasar Modern Jakarta Selatan. Agraris. 3(2), 67-75.

Beatie, B.R., \& Taylor, C.R. 1996. Ekonomi Produksi. Gadjah Mada University Press. Yogyakarta.
Cobb, C.W., \& Douglas, P.H. 1928. A Theory Production. American Economic Review.

Debertin, D.L. 2012. Agricultural Production Economic. Second Edition. David L. Debertin, University of Kentucky, Departement of Agricultural Economic.

Dlumini, D., Kongolo, \& Mukelo. 2014. Resources Use Efficiency Organik Vegetable Production: A Case study in Manzini Regions, Swaziland. Journal of Agricultural Study. 2(2), 52-61.

Ekananda, M. 2015. Ekenometrika Dasar untuk Bidang Sosial, Ekonomi dan Bisnis. Mitra Wacana Media.

Emas, R. 2015. The Concept Of Sustainable Development: Definition and Defining Principles. Florida International University. (1-3).

Ghozali, I. 2014. Ekonometrika: Teori, Konsep dan Aplikasi dengan IBM SPSS 22. Badan Penerbit UNDIP. Semarang.

Irianto, H., \& Mardikanto, T. 2011. Metoda Penelitian dan Evaluasi Agribisnis. UNS Press. Surakarta.

Krall, S. 2015.What is Sustainable Agriculture?. GIZ Germany.

Pearce, D., \& Turner, R. 1990. Economics of Natural Resources and the Environment. Harvester Wheatsheaf. New York, London, Toronto, Sydney Tokyo.

Prayitno, D. 2009. Mandiri Belajar SPSS. Buku Kita. Yogyakarta.

Prihtanti, T.M. 2016. Appreciation to Organik Agriculture Function: Case Study of Rice Farming. JEJAK Journal of Economics and Policy. 9(2), 279-296.

Rigby, D., \& Cacares, D. 2001. Organik Farming and Sustaibality of Agricultural Systems. Agricultral Systems. 68(1), 21-40.

Sanim, B., \& Sugema, I. 1996. Economic and Environmental Impact Assessment of the Implementation of Integrated Pest Management in West Java, a Case Vegetable Farm. Kongres XI dan Konpernas XII PERHEPI. Denpasar. 
Santoso, E. 2012. Rice organik farming is a Programme for Strengthening Food Security in Sustainable Rural Development. International Journal of Basic and Applied Science, 1(1), 16.

Sulistyana, P. 2014. Konsumsi Beras Organik pada Tingkat Rumah Tangga di Kota Yogyakarta. Universitas Gadjah Mada. Yogyakarta.

Suratiyah, K. 2015. Ilmu Usahatani: Edisi Revisi. Penebar Swadaya. Yogyakarta.

Surekha, K., Rao, K.V., Shobha, R.N., Latha, P.C., \& Kumar, R.M. 2013. Evaluation of Organic and Conventional Rice Production Systems for their Productivity, Profitability, Grain Quality and Soil Health. Agrotechnol S11: 006. doi:10.4172/2168-9881.S11-006.
Terano, R., Mohammad, Z., Syamsudin, M.N., \& Latif, I.A. 2015. Farm Sustaiability Indexs: The Case of Paddy Farmers in State of Kelantan Malaysia. Journal of the International Society for Southeast Asian Agricultural Sciences. 21(1), 55-67.

Tietenberg, T., \& Lewis L. 2012. Environmental and Natural Resouces Economics. $9^{\text {th }}$ Edition. Pearson.

Turner, R.K., Pearce, D., \& Batman, I. 1994. Environmental Economics. An Elementary Introduction. Harvester Wheatsheaf. New York, London, Toronto, Sydney Tokyo, Singapore.

Velten, S., Levento, J., Jeger, N., \& Newig, J. 2015. What is Sustainable Agriculture? Systematic Review. Sustainability. ISSN 20711050. www.mdpi.com/journal/sustainability. 